\title{
Safety, Pharmacokinetics and Pharmacodynamics of DS-1040, in Combination with Thrombectomy, in Japanese Patients with Acute Ischemic Stroke
}

\author{
Nobuyuki Sakai ${ }^{1} \cdot$ Masataka Takeuchi $^{2} \cdot$ Hirotoshi Imamura $^{1} \cdot$ Norihito Shimamura $^{3}$ - Shinichi Yoshimura ${ }^{4}$. \\ Hiromichi Naito ${ }^{5}$. Naoto Kimura ${ }^{6} \cdot$ Osamu Masuo $^{7} \cdot$ Nobuyuki Hirotsune $^{8} \cdot$ Kenichi Morita $^{9} \cdot$ Kazunori Toyoda $^{10}$. \\ Hiroshi Yamagami ${ }^{11}$ • Hideyuki Ishihara ${ }^{12}$. Takafumi Nakatsu ${ }^{13} \cdot$ Naoki Miyoshi $^{13} \cdot$ Miharu Suda $^{13}$. \\ Shigeru Fujimoto ${ }^{14}$
}

Accepted: 28 November 2021 / Published online: 21 January 2022

(c) The Author(s) 2022

\begin{abstract}
Background and Objectives DS-1040 is a novel inhibitor of the activated form of thrombin-activatable fibrinolysis inhibitor that may have therapeutic potential in thromboembolic diseases, such as acute ischemic stroke (AIS) or pulmonary embolism. We undertook a Phase I clinical trial to investigate the safety, pharmacokinetics, and pharmacodynamics of DS-1040 in Japanese patients who were eligible for thrombectomy following AIS.

Methods The trial enrolled patients with AIS due to large vessel occlusion, who were planned for thrombectomy within $8 \mathrm{~h}$ of symptom onset. Subjects were randomized to receive a single intravenous infusion of placebo or DS-1040 (0.6, 1.2, 2.4 or $4.8 \mathrm{mg}$ ) in a sequential-cohort design. The primary endpoints were the incidence of intracranial hemorrhage (ICH) and major extracranial bleeding within 36 and $96 \mathrm{~h}$, respectively, of treatment initiation. Treatment-emergent adverse events (TEAEs) and pharmacokinetic/pharmacodynamic parameters were also assessed.

Results Nine patients received placebo and 32 patients received DS-1040. There were no cases of symptomatic ICH or major extracranial bleeding with either placebo or DS-1040 after 36 and $96 \mathrm{~h}$. One patient, who received DS-1040 $0.6 \mathrm{mg}$, experienced a subarachnoid hemorrhage that was considered to be drug-related. Three patients died (2 placebo, 1 DS-1040), but no deaths were adjudicated as study drug-related. In vivo exposure to DS-1040 increased in proportion to dosage, but no clear dose-response relationship was seen for D-dimer levels and thrombin-activatable fibrinolysis inhibitor activity.

Conclusions Single doses of DS-1040 0.6-4.8 mg were well tolerated in Japanese patients with AIS undergoing thrombectomy.

Clinical trial registration number NCT03198715; JapicCTI-163164.
\end{abstract}

\section{Introduction}

Acute ischemic stroke (AIS) is a medical emergency and a major cause of death and disability worldwide. In Japan, approximately 195,000 cases of AIS occur each year, and there were over 90,000 deaths due to the disease in 2019 [1].

Stroke-related mortality is declining because of general improvements in the acute management of AIS, including the development of specialized stroke centers and the availability of effective revascularization with thrombolytic drugs

Nobuyuki Sakai

n.sakai@siren.ocn.ne.jp

Extended author information available on the last page of the article and endovascular therapy (thrombectomy) [2]. In a metaanalysis of five randomized controlled trials, thrombectomy was associated with a reduced risk of disability: $46 \%$ of patients who received thrombectomy had a favorable outcome (i.e., a modified Rankin Scale [mRS] score of 0-2 at 90 days), versus $26.5 \%$ of control patients $(p<0.0001)$ [3].

Higher rates of recanalization and the prevention of reocclusion are considered to be significant factors in improving outcomes in AIS [4-6], and the number of patients treated with thrombectomy is increasing. However, more needs to be done to improve outcomes in AIS, with data showing variable rates of recanalization and effects on prognosis [7]. For example, in the SWIFT PRIME trial, thrombectomy (using a stent retriever device) plus alteplase 


\section{Key Points}

DS-1040, a small-molecule inhibitor of the activated form of thrombin-activatable fibrinolysis inhibitor, has fibrinolytic activity and may improve reperfusion rates and prognostic indicators in patients with acute ischemic stroke (AIS).

We conducted a Phase I study to assess the safety/tolerability and pharmacokinetics/pharmacodynamics of DS-1040 in Japanese patients with AIS who were eligible for thrombectomy.

Single intravenous doses of DS-1040 (0.6-4.8 mg) were safe and well tolerated. There was limited evidence of a dose-effect relationship or marked differences between DS-1040 and placebo on pharmacodynamic parameters or scales measuring stroke severity or associated disability and, thus, further research is required to fully investigate the effects of DS-1040 in patients with AIS.

was associated with significantly higher recanalization rates (82.8\%) compared with alteplase alone [8]. However, the proportion of thrombectomy-treated patients with modified Rankin scores (mRS) of 0-2 at 90 days was only $60.2 \%$, indicating a discrepancy between recanalization and prognosis, and a need to continue the search for new treatment options.

DS-1040 is a novel, potent and selective inhibitor of the activated form of thrombin-activatable fibrinolysis inhibitor (TAFIa; also known as carboxypeptidase U) that has been shown to have fibrinolytic activity in animal models of thrombotic disease [9]. In healthy volunteers, DS-1040 (at doses of $\leq 40 \mathrm{mg}$ via IV infusion and $\leq 400 \mathrm{mg}$ orally) has been found to suppress TAFIa activity and increase D-dimer levels, with no effect on bleeding time, platelet aggregation or coagulation parameters $[10,11]$.

At the present time, data on the use of DS-1040 in patients with AIS are very limited, but it is hoped that the use of DS-1040 in combination with thrombectomy would improve reperfusion rates and prognostic indicators. As a first step in the clinical evaluation of DS-1040 for AIS, we conducted a Phase I trial to evaluate its safety, tolerability, pharmacokinetics, and pharmacodynamic effects in Japanese patients with AIS who were eligible for thrombectomy.

\section{Methods}

DS1040-A-J110 was a randomized, placebo-controlled, single-blind, dose-escalation trial undertaken to investigate the safety, pharmacokinetics, and pharmacodynamics of DS-1040 in patients with AIS who were eligible for thrombectomy (NCT03198715; JapicCTI-173612). The trial was performed at 20 centers in Japan (Supplementary Table S1; Online Resource 1) between July 2017 and January 2020 and was conducted in compliance with the Declaration of Helsinki, the International Conference on Harmonization Integrated Guideline for Good Clinical Practice, and additional regulatory codes applicable in Japan. The trial protocol was approved by the Institutional Review Board at each participating center before any patients were enrolled at that center. All patients, or a legally competent representative, gave written informed consent to participate.

\subsection{Inclusion and Exclusion Criteria}

Complete inclusion and exclusion criteria are listed in Supplementary Table S2 (Online Resource 1).

AIS patients aged 20-89 years were screened for enrollment. To be included, patients had to have angiogram-confirmed (by computed tomography or magnetic resonance imaging) internal carotid artery (ICA) or middle cerebral artery (MCA; M1 region) occlusion, for which thrombectomy was planned as the primary treatment modality. Only those considered able to receive thrombectomy within $8 \mathrm{~h}$ of the onset of ischemic symptoms were included. Additionally, patients had to have a National Institutes of Health Stroke Scale (NIHSS) score of $\geq 6$ and an Alberta Stroke Program Early CT Score of $\geq 6$.

Patients were excluded if they: (i) were planned for, or had received, thrombolytic therapy; (ii) had evidence of (or risk factors for) hemorrhagic stroke, or other major bleeding event; (iii) had severe renal or hepatic impairment; or (iv) had a contraindication to thrombectomy. DS-1040 was not used in combination with thrombolytic therapy because of the potential for bleeding events.

\subsection{Study Design}

The study design is shown in Fig. 1. Patients were enrolled in four sequential cohorts. Cohort 1 consisted of six patients, all of whom received a single dose of DS-1040 $0.6 \mathrm{mg}$. The study design allowed for a further six patients to be recruited into this cohort if study discontinuation or interruption criteria were met (Supplementary Table S3; Online Resource 1). On the basis of previous modeling and simulation work in healthy volunteers, we calculated that a DS-1040 dosage of $1.2 \mathrm{mg}$ would achieve maximum plasma drug concentrations $\left(C_{\max }\right)$ of $23.8-31.7 \mathrm{ng} / \mathrm{mL}$, versus a reported $90 \%$ of the maximal inhibitory concentration $\left(\mathrm{IC}_{90}\right)$ of 38.2 $\mathrm{ng} / \mathrm{mL}$ in clot lysis assays [10]. We adopted a conservative approach and selected $0.6 \mathrm{mg}$ as the starting dose, due to the lack of safety data in the Japanese population. Cohorts 2, 3 and 4 each consisted of 16 patients, randomized by 


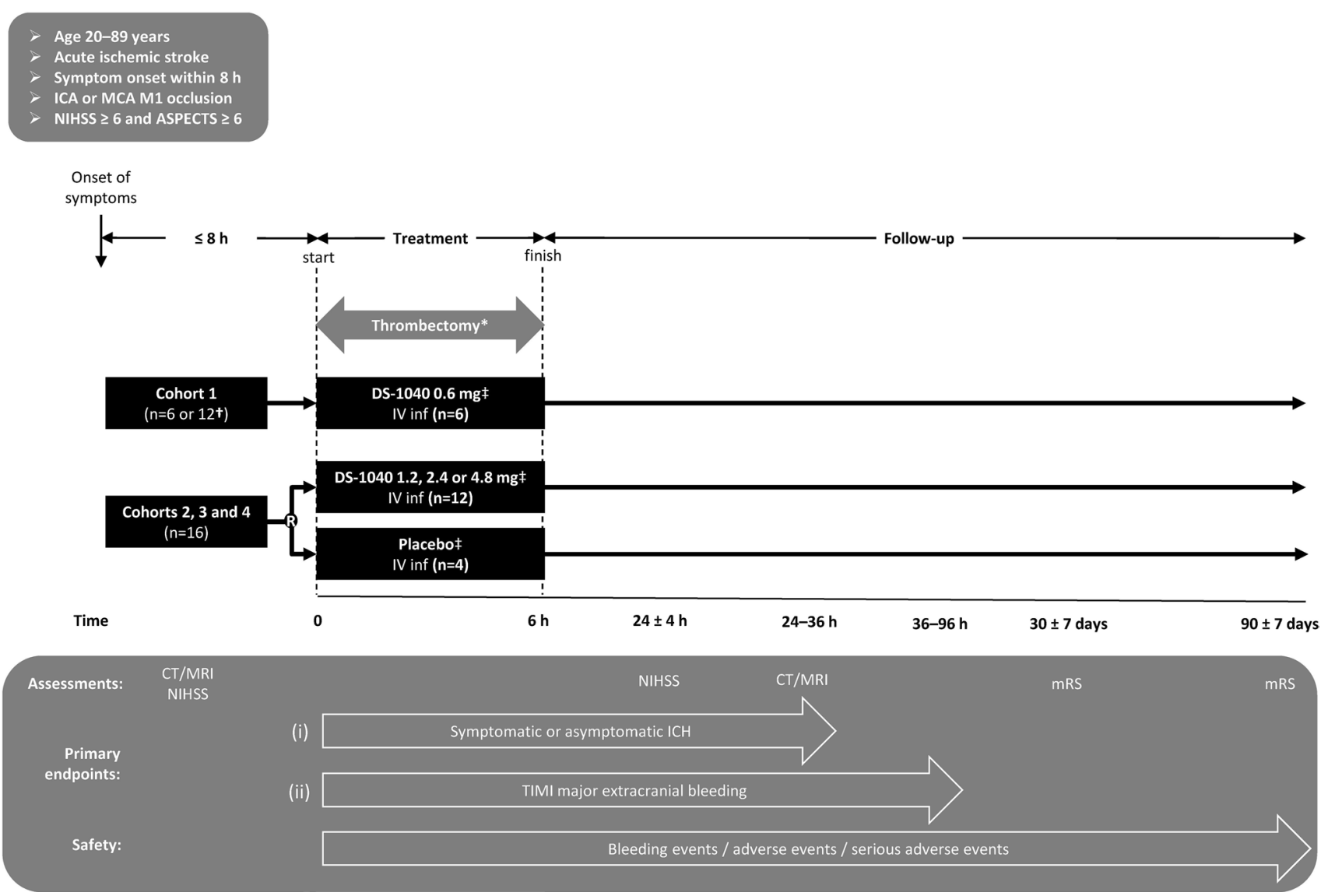

Fig. 1 Study design. *Performed within $8 \mathrm{~h}$ of the onset of symptoms. ${ }^{\dagger}$ The study design allowed for an additional six patients to be recruited into Cohort 1 if study discontinuation or interruption criteria were met (Supplementary Table S2; Online Resource 1). ${ }^{\ddagger}$ Started before thrombectomy, or as soon as possible afterwards. ASPECTS

block assignment to the DS-1040 (1.2 mg, $2.4 \mathrm{mg}$, or 4.8 $\mathrm{mg}$, respectively) or placebo groups in a 3:1 ratio. Thus, the total planned enrollment was 54 or 60 patients, depending on the outcome of Cohort 1.

Enrollment into Cohorts 2, 3 and 4 began once all patients in the previous cohort had completed $96 \mathrm{~h}$ of follow-up, and an evaluation of the available safety data at that time-point supported the continuation of the trial. Within each cohort, patients were evaluated at $36 \mathrm{~h}$ for the presence of symptomatic intracerebral hemorrhage (ICH) before the next patient was enrolled. This continued until three patients aged $\geq 81$ years (considered to be at higher risk of bleeding events) had been randomized to receive DS-1040 in each cohort.

\subsection{Treatment}

Both DS-1040 and placebo were administered by intravenous (IV) infusion over $6 \mathrm{~h}$. Each dose of DS-1040 was added to $100 \mathrm{~mL}$ normal saline for infusion; placebo infusions consisted of $100 \mathrm{~mL}$ normal saline only. The first $25 \%$
Alberta Stroke Program Early CT Score, $C T$ computed tomography, $I C A$ internal carotid artery, $I V$ inf intravenous infusion, $M C A$ middle cerebral artery, $M R I$ magnetic resonance imaging, $m R S$ modified Rankin Scale, NIHSS National Institutes of Health Stroke Scale, TIMI Thrombolysis in Myocardial Infarction

of each dose was administered over $30 \mathrm{~min}$, and the remaining $75 \%$ over $5.5 \mathrm{~h}$. DS-1040 was supplied to each study center by Daiichi Sankyo Co., Ltd. (Tokyo, Japan). Placebo supplies were taken from IV fluid stocks at each center.

Study treatment was started within $8 \mathrm{~h}$ of symptom onset, prior to thrombectomy or as soon as possible afterwards. Except for monotherapy with aspirin (acetylsalicylic acid), clopidogrel or enoxaparin, and heparin used in connection with thrombectomy, drugs with thrombolytic, antiplatelet, or anticoagulant activity were prohibited until $24 \mathrm{~h}$ after the start of study treatment.

\subsection{Outcomes}

Patients were followed up for 90 days from the date of study treatment. The main objective of the trial was to assess the safety of DS-1040; accordingly, the primary endpoints were: (i) the incidence of symptomatic (according to the European Cooperative Acute Stroke Study [ECASS] criteria) and asymptomatic ICH within $36 \mathrm{~h}$ of starting study treatment; 
and (ii) extracranial (Thrombolysis in Myocardial Infarction [TIMI]) major bleeding within $96 \mathrm{~h}$ of starting study treatment. The ECASS definition of symptomatic ICH is $\mathrm{ICH}$ with clinical deterioration causing an increase in the NIHSS score of $\geq 4$ points, and the definition of TIMI major bleeding is clinically evident bleeding with a $5 \mathrm{~g} / \mathrm{dL}$ or greater decrease in hemoglobin; a 2-unit blood transfusion (where 1 unit is equivalent to $200 \mathrm{~mL}$ ) was converted to a $1 \mathrm{~g} / \mathrm{dL}$ increase in hemoglobin. The final classification and assessment of hemorrhagic events was performed by a central adjudication committee member who was blinded to the patient's treatment allocation.

Secondary endpoints were: (i) treatment-emergent adverse events (TEAEs); (ii) pharmacokinetic parameters, calculated using a non-compartmental model and DS-1040 concentrations measured in plasma; (iii) pharmacodynamic parameters (D-dimer levels and TAFIa activity); (iv) change in NIHSS score from baseline to $24( \pm 4) \mathrm{h}$ after the start of study treatment; and (v) the proportion of patients with a favorable outcome (defined as a $\mathrm{mRS}$ score of 0,1 , or 2 ) at 30 and 90 days. Pharmacokinetic parameters and dose proportionality were calculated using WinNonlin ${ }^{\mathrm{TM}}$ version 6.0 or higher (Certara, Princeton, NJ, USA).

As an exploratory endpoint, we investigated the proportion of patients achieving complete (i.e., modified Thrombolysis in Cerebral Infarction [TICI] grade 3 [12]) reperfusion after thrombectomy, and the impact of DS-1040 on the proportion of patients with TICI grade 3 .

\subsubsection{Adverse Events}

Information on AEs was collected at all study visits, including the day of study drug administration (Visit 1). AEs were defined as untoward medical occurrences, without regard to causality. An AE was considered to be serious if: (i) it was life-threatening; (ii) it was fatal; (iii) it resulted in hospitalization or prolongation of existing hospitalization; (iv) it resulted in persistent or significant disability or incapacity; or (iii) it was otherwise considered important. TEAEs were defined as AEs that were not present prior to the study but developed between the start of study treatment and Day 30 (Visit 5).

\subsubsection{Bioanalytical Assay}

Blood samples for pharmacokinetic analysis were taken before the start of study drug administration, and at 0.5, $3,6,18,24,48$ and $96 \mathrm{~h}$ after the start of treatment. For measurement of plasma DS-1040 concentrations, $3 \mathrm{~mL}$ of venous or arterial blood from each subject was collected in $\mathrm{K}_{2}$-EDTA tubes. After blood collection, tubes were mixed by inversion immediately and then cooled with ice. Plasma was obtained by centrifugation $\left(4^{\circ} \mathrm{C}, 1500 \times g, 15 \mathrm{~min}\right)$ and was stored at or below $-20{ }^{\circ} \mathrm{C}$ until analysis.

The assay method was validated for a range of concentrations between 0.500 and $500 \mathrm{ng} / \mathrm{mL}$, based on the analysis of $0.100 \mathrm{~mL}$ of plasma. DS-1040 and its internal standard were extracted from plasma samples $(0.100 \mathrm{~mL})$ through solid phase extraction using $\operatorname{Strata}^{\circledR} \operatorname{SCX}(55 \mu \mathrm{m}, 70 \AA), 50 \mathrm{mg}$ / well solid phase extraction plates (Phenomenex, Torrance, CA, USA). The final eluent was evaporated to dryness, and the reconstituted extract was injected into a Sciex API $4000^{\mathrm{TM}}$ (AB Sciex, Framingham, MA, USA) tandem mass spectrometer with turbo ion spray source by electrospray ionization in the positive ion mode. Multiple-reaction monitoring of DS-1040 $(\mathrm{m} / \mathrm{z} 294 \rightarrow 180)$ and its internal standard DS-1040-D4 $(\mathrm{m} / \mathrm{z} 298 \rightarrow 184)$ was conducted using an HPLC column. Chromatographic separation was performed using a Luna C18(2) $3 \mu \mathrm{m}, 100 \times 2.0 \mathrm{~mm}$ column (Phenomenex). The assay accuracy was in the range $-6.4 \%$ to $-1.3 \%$, and the lower limit of quantification was $0.5 \mathrm{ng} / \mathrm{mL}$.

Blood samples for pharmacodynamic analysis were taken before the start of study drug administration and at 6, 24 and $48 \mathrm{~h}$ afterwards. On each occasion, $9 \mathrm{~mL}$ of venous blood was collected in sodium citrate $3.2 \%$ tubes, which were immediately mixed by inversion. D-dimer was measured using the STA ${ }^{\circledR}$-Liatest ${ }^{\circledR}$ D-Di assay, while TAFIa activity was measured using the STA ${ }^{\circledR}$-Stachrom ${ }^{\circledR}$ TAFI assay (both manufactured by Diagnostica Stago S.A.S., Asnières sur Seine, France).

D-dimer levels were reported in $\mu \mathrm{g} / \mathrm{mL}$ fibrinogen equivalent units (FEU), over an analytical measuring range (AMR) of $0.36-4.00 \mu \mathrm{g} / \mathrm{mL}$ FEU. Samples with results below the AMR were reported as $<0.36 \mu \mathrm{g} / \mathrm{mL}$ FEU; those with results $>4.00 \mu \mathrm{g} / \mathrm{mL}$ FEU were re-assayed after diluting up to 5-fold using Owren-Koller buffer, and the results multiplied by the corresponding dilution factor. The reference range for D-dimer in citrated plasma is $<0.50 \mu \mathrm{g} / \mathrm{mL}$ FEU. TAFIa was measured and reported as a percentage, with an AMR of 9-137\% and a reference range of 77-177\%. Samples with results below the AMR were reported as $<9 \%$, and those $>137 \%$ were re-assayed after diluting up to 8-fold using Owren-Koller buffer.

\subsection{Statistical Analysis}

Safety analyses were performed on the safety analysis set, defined as the population of enrolled patients who received at least one dose of study treatment. For all endpoints, including the primary endpoints, point estimates were calculated for each dosage of DS-1040, and for all placebo recipients as a single group. For TEAEs, incidences were calculated for each treatment group. Pharmacokinetic and pharmacodynamic parameters were assessed for all patients without major protocol violations and with at least one 
plasma concentration or pharmacodynamic measurement, respectively. Summary statistics on plasma concentrations, pharmacokinetic parameters and pharmacodynamic measurements were calculated for each treatment group.

Measures of efficacy (i.e., change in NIHSS score from baseline to $24 \mathrm{~h}$; proportion with favorable outcome at 30 and 90 days) were assessed for the full analysis set, which included all patients who received study treatment and for whom relevant NIHSS or mRS data were available. Summary statistics were calculated for efficacy endpoints.

All statistical analyses were performed using SAS ${ }^{\circledR}$ version 9.4 or higher (SAS Institute, Cary, NC, USA).

\section{Results}

\subsection{Patient Disposition}

Enrollment into DS1040-A-J110 was stopped while the trial was in progress because the sponsor decided to discontinue the late-stage development of DS-1040. ${ }^{1}$ At this point, Cohorts 1, 2, and 3 had been fully recruited. Four of the planned 16 patients had been enrolled in Cohort 4: three patients were randomized to DS-1040 $4.8 \mathrm{mg}$ and one patient was randomized to placebo.

Forty-two patients were randomized (33 to DS-1040 and 9 to placebo), and only one patient (in the DS-1040 $2.4 \mathrm{mg}$ group) did not receive study drug (Supplementary Figure S1; Online Resource 1). Thus, the safety analysis set, and full analysis set both included 41 patients.

No events occurred that would have triggered the recruitment of additional patients into Cohort 1 . Recruitment into Cohort 2 was therefore able to begin once the first six patients in Cohort 1 had completed $96 \mathrm{~h}$ of follow-up.

Five patients discontinued the study. Discontinuation was due to death in three patients (one patient who received DS-1040 $2.4 \mathrm{mg}$, and two patients who received placebo), none of which were judged to be related to study drug. Additionally, one patient in the $1.2 \mathrm{mg}$ group was withdrawn from the study because of a suspected protocol violation relating to the exclusion criteria; another patient (in the 2.4mg group; already described above) was withdrawn before treatment started because angiography suggested a risk of hemorrhage.

\footnotetext{
1 The addition of DS-1040 to enoxaparin did not result in improved efficacy compared with enoxaparin alone in a Phase II trial in patients with acute pulmonary embolism (NCT02923115) [13].
}

\subsection{Patient Characteristics}

There were no important differences between the study groups at baseline (Table 1). Patients in the safety analysis set had a mean ( \pm standard deviation $[\mathrm{SD}])$ age of $74.5 \pm$ 9.0 (range 53.0-87.0) years, and approximately half (46.3\%) were female. NIHSS scores ranged from 6 to 33, and median scores were similar for DS-1040 and placebo recipients (20.0 vs 21.5 , respectively).

\subsection{Primary Endpoints}

Rates of ICH and major extracranial bleeding are shown in Table 2. There were no cases of symptomatic ICH in the $36 \mathrm{~h}$ after the start of treatment among either DS-1040 or placebo recipients. Similarly, no cases of major extracranial bleeding were reported in the first $96 \mathrm{~h}$. The incidence of asymptomatic ICH was 37.5\% among DS-1040 recipients and $11.1 \%$ among placebo recipients; no relationship between DS-1040 dose and incidence of asymptomatic ICH was seen.

\subsection{Secondary Endpoints}

\subsubsection{Adverse Events}

TEAEs are summarized in Table 3. Overall, DS-1040 was well tolerated: although most patients (35/41 patients; 85.4\%) experienced AEs, only one TEAE (a subarachnoid hemorrhage in a patient who received DS-1040 $0.6 \mathrm{mg}$ ) was considered to be study drug-related and was not categorized as serious. Overall, TEAEs classed as serious occurred infrequently (reported in five [12.2\%] patients), and none were considered related to study drug. Furthermore, there were no serious bleeding events, and no discontinuations of study drug due to a TEAE in any treatment group.

Among DS-1040 recipients, there was no clear evidence of a dose-proportional increase in TEAEs (Table 3). The most frequent TEAEs (i.e. those reported in $>10 \%$ [i.e. $>3$ ] of DS-1040 recipients) were constipation ( $25.0 \%$ vs $33.3 \%$ with placebo), hemorrhagic infarction $(25.0 \%$ vs $0.0 \%)$, skin exfoliation (15.6\% vs $0.0 \%)$ and pneumonia aspiration (12.5\% vs $22.2 \%)$.

Three patients died during the trial; all deaths were considered unrelated to study drug. One patient who received DS-1040 $2.4 \mathrm{mg}$ had an acute myocardial infarction 9 days after study drug administration. The other two deaths were in placebo recipients; these were due to aspiration pneumonia in one patient and an exacerbation of right lung adenocarcinoma in the other. 
Table 1 Patient characteristics for the safety analysis set $(n=41$; all patients who were randomized and received at least one dose of study drug)

\begin{tabular}{|c|c|c|c|c|c|c|c|}
\hline \multirow[t]{2}{*}{ Parameter } & \multirow[t]{2}{*}{ Placebo $(n=9)$} & \multicolumn{5}{|c|}{ DS-1040 $(n=32)$} & \multirow[t]{2}{*}{ Overall $(n=41)$} \\
\hline & & $0.6 \mathrm{mg}(n=6)$ & $1.2 \mathrm{mg}(n=12)$ & $2.4 \mathrm{mg}(n=11)$ & $4.8 \mathrm{mg}(n=3)$ & Total $(n=32)$ & \\
\hline Mean \pm SD age, years & $76.9 \pm 11.2$ & $71.5 \pm 6.8$ & $76.3 \pm 7.0$ & $73.6 \pm 10.4$ & $69.0 \pm 7.8$ & $73.8 \pm 8.3$ & $74.5 \pm 9.0$ \\
\hline Female, $n(\%)$ & $5(55.6)$ & $2(33.3)$ & $5(41.7)$ & $5(45.5)$ & $2(66.7)$ & $14(43.8)$ & $19(46.3)$ \\
\hline $\begin{array}{l}\text { Mean } \pm \text { SD body } \\
\text { weight, } \mathrm{kg}\end{array}$ & $55.6 \pm 19.1$ & $63.1 \pm 16.3$ & $64.2 \pm 15.1$ & $58.7 \pm 12.3$ & $50.9 \pm 13.0$ & $60.9 \pm 14.1$ & $59.7 \pm 15.3$ \\
\hline $\begin{array}{l}\text { Median (range) NIHSS } \\
\text { score }\end{array}$ & $20.0(10-26)$ & $14.5(6-26)$ & $25.0(11-33)$ & $20.0(9-28)$ & $27.0(8-28)$ & $21.5(6-33)$ & $20.0(6-33)$ \\
\hline $\begin{array}{l}\text { Median (range) } \\
\text { ASPECTS score }\end{array}$ & $7.0(6-10)$ & $6.5(6-8)$ & $7.0(6-9)$ & $7.0(6-10)$ & $8.0(6-8)$ & $7.0(6-10)$ & $7.0(6-10)$ \\
\hline $\begin{array}{l}\text { History of ischemic } \\
\text { stroke, } n(\%)\end{array}$ & $3(33.3)$ & $1(16.7)$ & $1(8.3)$ & $3(27.3)$ & $1(33.3)$ & $6(18.8)$ & $9(22.0)$ \\
\hline \multicolumn{8}{|l|}{ Site of occlusion, $n(\%)$} \\
\hline ICA & $3(33.3)$ & $1(16.7)$ & $4(33.3)$ & $5(41.7)$ & $0(0.0)$ & $10(30.3)$ & $13(31.0)$ \\
\hline MCA M1 & $6(66.7)$ & $5(83.3)$ & $8(66.7)$ & $6(50.0)$ & $3(100.0)$ & $22(66.7)$ & $28(66.7)$ \\
\hline
\end{tabular}

ASPECTS Alberta Stroke Program Early Computed Tomography Score, ICA internal carotid artery, MCA M1 middle cerebral artery, M1 region, NIHSS National Institutes of Health Stroke Scale, SD standard deviation

Table 2 Bleeding events in the first $96 \mathrm{~h}$. Multiple events in a single patient were evaluated separately, hence the total number of events may be greater than the number of patients in each cohort

\begin{tabular}{|c|c|c|c|c|c|c|c|}
\hline \multirow[t]{2}{*}{ Type of bleeding, n (\%) } & \multirow[t]{2}{*}{ Placebo $(n=9)$} & \multicolumn{5}{|c|}{ DS-1040 $(n=32)$} & \multirow[t]{2}{*}{ Overall $(n=41)$} \\
\hline & & $0.6 \mathrm{mg}(n=6)$ & $1.2 \mathrm{mg}(n=12)$ & $2.4 \mathrm{mg}(n=11)$ & $4.8 \mathrm{mg}(n=3)$ & Total $(n=32)$ & \\
\hline Symptomatic ICH & 0 & 0 & 0 & 0 & 0 & 0 & 0 \\
\hline Asymptomatic ICH & $1(11.1)$ & $2(66.7)$ & $5(41.7)$ & $4(36.4)$ & $1(33.3)$ & $12(37.5)$ & $13(31.7)$ \\
\hline \multicolumn{8}{|l|}{$\begin{array}{l}\text { ECASS } 2 \text { classification } \\
\text { of asymptomatic ICH }\end{array}$} \\
\hline $\begin{array}{l}\text { Hemorrhagic infarc- } \\
\text { tion, type } 1^{\mathrm{a}}\end{array}$ & 0 & 0 & $1(8.3)$ & 0 & 0 & $1(3.1)$ & $1(2.4)$ \\
\hline $\begin{array}{l}\text { Hemorrhagic infarc- } \\
\text { tion, type } 2^{\mathrm{b}}\end{array}$ & 0 & $1(33.3)$ & $1(8.3)$ & $1(9.1)$ & 0 & $3(9.4)$ & $3(7.3)$ \\
\hline $\begin{array}{l}\text { Parenchymal hema- } \\
\text { toma, type } 1^{\mathrm{c}}\end{array}$ & 0 & 0 & $3(25.0)$ & 0 & $1(33.3)$ & $4(12.5)$ & $4(9.8)$ \\
\hline $\begin{array}{l}\text { Parenchymal hema- } \\
\text { toma, type } 2^{\mathrm{d}}\end{array}$ & 0 & 0 & 0 & $2(18.2)$ & 0 & $2(6.25)$ & $2(4.9)$ \\
\hline Other diagnosis & $1(11.1)$ & $1(33.3)$ & $1(8.3)$ & $1(9.1)$ & 0 & $3(9.4)$ & $4(9.8)$ \\
\hline $\begin{array}{l}\text { Major extracranial } \\
\text { bleeding }\end{array}$ & 0 & 0 & 0 & 0 & 0 & 0 & 0 \\
\hline Other bleeding event & $5(55.6)$ & $3(50.0)$ & $5(41.7)$ & 7 (63.6) & $1(33.3)$ & $16(50.0)$ & $21(51.2)$ \\
\hline
\end{tabular}

ECASS European Cooperative Acute Stroke Study, ICH intracranial hemorrhage

${ }^{a}$ Small petechial hemorrhage along the margins of the infarct

${ }^{b}$ Confluent petechial hemorrhage within the infarcted area, but without a mass effect

${ }^{c}$ Hematoma involving $\leq 30 \%$ of the infarcted area with a slight mass effect

${ }^{\mathrm{d}}$ Hematoma involving $>30 \%$ of, or outside, the infarcted area, with a significant mass effect

\subsubsection{Pharmacokinetics}

The plasma concentration-time curves for each dosage of DS-1040 are shown in Fig. 2, and calculated pharmacokinetic parameters are summarized in Table 4. In vivo exposure to DS-1040 (measured as the area under the plasma concentration-time curve [AUC]) increased in a dose-proportional manner, as did $C_{\max }$. As expected, mean time to $C_{\max }$ increased with dosage, from $2.21 \mathrm{~h}$ at a dosage of 0.6 $\mathrm{mg}$ to $5.96 \mathrm{~h}$ at a dosage of $4.8 \mathrm{mg}$. The mean elimination half-life $\left(t_{1 / 2}\right)$ and volume of distribution at steady state $\left(V_{\mathrm{ss}}\right)$ of DS-1040 also showed dose-dependency, increasing from 
Table 3 Treatment-emergent adverse events (TEAEs). In the analysis of TEAEs by preferred term, only those TEAEs that occurred in at least 2 patients in any treatment group (i.e. with placebo, with any individual dosage of DS-1040, or with DS-1040 overall) are included, and are listed in descending order by system organ class for DS-1040 recipients (i.e. the second-to-last column from the right)

\begin{tabular}{|c|c|c|c|c|c|c|c|}
\hline \multirow{2}{*}{$\begin{array}{l}\text { Type of adverse event } \\
\text { (AE), } n(\%)\end{array}$} & \multirow[t]{2}{*}{ Placebo $(n=9)$} & \multicolumn{5}{|c|}{ DS-1040 $(n=32)$} & \multirow[t]{2}{*}{ Overall $(n=41)$} \\
\hline & & $0.6 \mathrm{mg}(n=6)$ & $1.2 \mathrm{mg}(n=12)$ & $2.4 \mathrm{mg}(n=11)$ & $4.8 \mathrm{mg}(n=3)$ & Total $(n=32)$ & \\
\hline \multicolumn{8}{|l|}{ Overall results } \\
\hline Any AE & $8(88.9)$ & $5(83.3)$ & $10(83.3)$ & $10(90.9)$ & $2(66.7)$ & $27(84.4)$ & $35(85.4)$ \\
\hline TEAE & $8(88.9)$ & $5(83.3)$ & $10(83.3)$ & $10(90.9)$ & $2(66.7)$ & $27(84.4)$ & $35(85.4)$ \\
\hline Drug-related TEAE & $0(0.0)$ & $1(16.7)$ & $0(0.0)$ & $0(0.0)$ & $0(0.0)$ & $1(3.1)$ & $1(2.4)$ \\
\hline Bleeding TEAE ${ }^{\mathrm{a}}$ & $6(66.7)$ & $3(50.0)$ & $6(50.0)$ & $9(81.8)$ & $2(66.7)$ & $20(62.5)$ & $26(63.4)$ \\
\hline $\begin{array}{l}\text { Drug-related bleeding } \\
\text { TEAE }^{\mathrm{a}}\end{array}$ & $0(0.0)$ & $1(16.7)$ & $0(0.0)$ & $0(0.0)$ & $0(0.0)$ & $1(3.1)$ & $1(2.4)$ \\
\hline Serious TEAE & $1(11.1)$ & $0(0.0)$ & $2(16.7)$ & $2(18.2)$ & $0(0.0)$ & $4(12.5)$ & $5(12.2)$ \\
\hline \multicolumn{8}{|c|}{ Analysis by system organ class and preferred term } \\
\hline \multicolumn{8}{|c|}{ Gastrointestinal disorders } \\
\hline Constipation & $3(33.3)$ & $2(33.3)$ & $2(16.7)$ & $3(27.3)$ & $1(33.3)$ & $8(25.0)$ & $11(26.8)$ \\
\hline Gingival bleeding & $1(11.1)$ & $0(0.0)$ & $1(8.3)$ & $1(9.1)$ & $0(0.0)$ & $2(6.3)$ & $3(7.3)$ \\
\hline Vomiting & $1(11.1)$ & $2(33.3)$ & $0(0.0)$ & $0(0.0)$ & $0(0.0)$ & $2(6.3)$ & $3(7.3)$ \\
\hline \multicolumn{8}{|c|}{ Nervous system disorders } \\
\hline $\begin{array}{l}\text { Subarachnoid hemor- } \\
\text { rhage }\end{array}$ & $1(11.1)$ & $1(16.7)$ & $1(8.3)$ & $1(9.1)$ & $0(0.0)$ & $3(9.4)$ & $4(9.8)$ \\
\hline $\begin{array}{l}\text { Hemorrhagic cerebral } \\
\text { infarction }\end{array}$ & $0(0.0)$ & $0(0.0)$ & $1(8.3)$ & $1(9.1)$ & $1(33.3)$ & $3(9.4)$ & $3(7.3)$ \\
\hline \multicolumn{8}{|c|}{ Skin and subcutaneous tissue disorders } \\
\hline Dermatitis diaper & $2(22.2)$ & $1(16.7)$ & $2(16.7)$ & $0(0.0)$ & $0(0.0)$ & $3(9.4)$ & $5(12.2)$ \\
\hline Skin exfoliation & $0(0.0)$ & $1(16.7)$ & $3(25.0)$ & $1(9.1)$ & $0(0.0)$ & $5(15.6)$ & $5(12.2)$ \\
\hline \multicolumn{8}{|l|}{ Vascular disorders } \\
\hline $\begin{array}{l}\text { Hemorrhagic infarc- } \\
\text { tion }\end{array}$ & $0(0.0)$ & $1(16.7)$ & $5(41.7)$ & $2(18.2)$ & $0(0.0)$ & $8(25.0)$ & $8(19.5)$ \\
\hline Hemorrhage & $0(0.0)$ & $0(0.0)$ & $0(0.0)$ & $2(18.2)$ & $0(0.0)$ & $2(6.3)$ & $2(4.9)$ \\
\hline \multicolumn{8}{|c|}{ Renal and urinary disorders } \\
\hline $\begin{array}{l}\text { Hemorrhage urinary } \\
\text { tract }\end{array}$ & $1(11.1)$ & $0(0.0)$ & $1(8.3)$ & $2(18.2)$ & $0(0.0)$ & $3(9.4)$ & $4(9.8)$ \\
\hline Hematuria & $1(11.1)$ & $1(16.7)$ & $0(0.0)$ & $1(9.1)$ & $0(0.0)$ & $2(6.3)$ & $3(7.3)$ \\
\hline \multicolumn{8}{|c|}{ Respiratory, thoracic, and mediastinal disorders } \\
\hline Pneumonia aspiration & $2(22.2)$ & $1(16.7)$ & $2(16.7)$ & $1(9.1)$ & $0(0.0)$ & $4(12.5)$ & $6(14.6)$ \\
\hline \multicolumn{8}{|c|}{ General disorders and administration site conditions } \\
\hline Pyrexia & $1(11.1)$ & $1(16.7)$ & $0(0.0)$ & $2(18.2)$ & $0(0.0)$ & $3(9.4)$ & $4(9.8)$ \\
\hline $\begin{array}{l}\text { Vessel puncture site } \\
\text { hematoma }\end{array}$ & $0(0.0)$ & $1(16.7)$ & $1(8.3)$ & $0(0.0)$ & $0(0.0)$ & $2(6.3)$ & $2(4.9)$ \\
\hline \multicolumn{8}{|l|}{ Infections and infestations } \\
\hline Urinary tract infection & $2(22.2)$ & $0(0.0)$ & $1(8.3)$ & $1(9.1)$ & $0(0.0)$ & $2(6.3)$ & $4(9.8)$ \\
\hline $\begin{array}{l}\text { Respiratory tract } \\
\text { infection }\end{array}$ & $2(22.2)$ & $0(0.0)$ & $0(0.0)$ & $0(0.0)$ & $0(0.0)$ & $0(0.0)$ & $2(4.9)$ \\
\hline \multicolumn{8}{|c|}{ Injury, poisoning, and procedural complications } \\
\hline $\begin{array}{l}\text { Subcutaneous hema- } \\
\text { toma }\end{array}$ & $2(22.2)$ & $0(0.0)$ & $1(8.3)$ & $1(9.1)$ & $1(33.3)$ & $3(9.4)$ & $5(12.2)$ \\
\hline \multicolumn{8}{|l|}{ Psychiatric disorders } \\
\hline Insomnia & $0(0.0)$ & $0(0.0)$ & $0(0.0)$ & $2(18.2)$ & $1(33.3)$ & $3(9.4)$ & $3(7.3)$ \\
\hline Delirium & $0(0.0)$ & $0(0.0)$ & $2(16.7)$ & $0(0.0)$ & $0(0.0)$ & $2(6.3)$ & $2(4.9)$ \\
\hline \multicolumn{8}{|c|}{ Metabolism and nutrition disorders } \\
\hline Hypokalemia & $0(0.0)$ & $0(0.0)$ & $2(16.7)$ & $0(0.0)$ & $0(0.0)$ & $2(6.3)$ & $2(4.9)$ \\
\hline
\end{tabular}

${ }^{\mathrm{a}}$ As judged by a member of the central adjudication committee 
Fig. 2 Plasma concentrationtime curves for DS-1040. The dashed horizontal line signifies the concentration of DS-1040 $(38 \mathrm{ng} / \mathrm{mL})$ at which $90 \%$ maximal clot lysis was achieved in healthy volunteers [10]. Data points and error bars show the mean \pm standard deviation

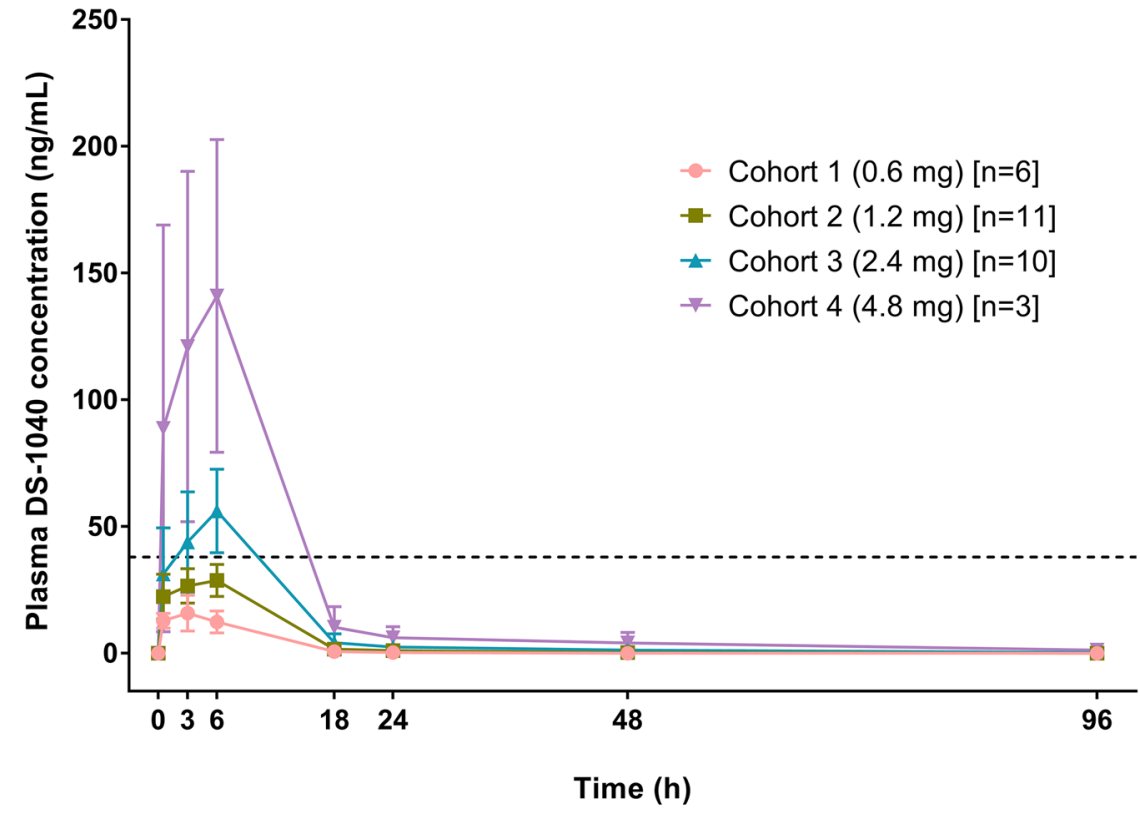

Number of samples Cohort 1 (0.6 mg) Cohort $2(1.2 \mathrm{mg})$ Cohort $3(2.4 \mathrm{mg})$ Cohort $4(4.8 \mathrm{mg})$

$\begin{array}{rr}5 & 6 \\ 10 & 11 \\ 10 & 10 \\ 3 & 3\end{array}$

6

10

10

3
$4.61 \mathrm{~h}$ and 17.6 L, respectively, in Cohort $1(n=1)$ to 29.7 $\mathrm{h}$ and $46.5 \mathrm{~L}$, respectively, in Cohort $4(n=3)$.

\subsubsection{Pharmacodynamics}

D-dimer levels and TAFIa activity are shown in Fig. 3. At baseline, mean \pm SD D-dimer levels were higher and showed greater variance in patients who received placebo than in those who received DS- $1040(3.1 \pm 6.8$ vs $1.3 \pm 2.8$ $\mu \mathrm{g} / \mathrm{mL}$ FEU), but TAFIa activity was similar in both groups.

D-dimer levels increased by similar amounts between baseline and $24 \mathrm{~h}$ in the placebo and DS-1040 groups (mean change +0.28 vs $+0.35 \mu \mathrm{g} / \mathrm{mL}$ FEU, respectively). Furthermore, mean increases in D-dimer levels were smaller in patients who received DS-1040 $4.8 \mathrm{mg}$ than in those who received $2.4 \mathrm{mg}(+0.45 \mathrm{vs}+1.18 \mu \mathrm{g} / \mathrm{mL}$ FEU at $24 \mathrm{~h}$ and $+0.67 \mathrm{vs}+1.03 \mu \mathrm{g} / \mathrm{mL}$ FEU at $48 \mathrm{~h}$ ). However, consistent with its mechanism of action, doses of DS-1040 above 1.2 $\mathrm{mg}$ were associated with decreases in TAFIa activity at $6 \mathrm{~h}$. There was evidence of a dose-response relationship at $6 \mathrm{~h}$, since greater decreases in activity were seen with DS-1040 $4.8 \mathrm{mg}$ than at lower doses, but this difference tended to disappear at later time-points.

\subsubsection{NIHSS and mRS Scores}

Mean changes in NIHSS score between baseline and 24 $\mathrm{h}$ are shown in Fig. 4. Although DS-1040 was associated with reductions in NIHSS score at all dose levels, there was no strong evidence of dose proportionality; furthermore, the magnitude of change was comparable for placebo and DS-1040 doses up to $2.4 \mathrm{mg}$.

Among DS-1040 recipients, the proportion of patients with a favorable outcome (mRS score 0-2) was $43.8 \%$ (95\% confidence interval [CI]: $26.4-62.3 \%)$ and $53.1 \%$ (95\% CI $34.7-70.9 \%)$ at 30 and 90 days, respectively. Values for placebo were $11.1 \%(95 \%$ CI $0.3-48.2 \%)$ at 30 days and $33.3 \%$ (95\% CI 7.5-70.1\%) at 90 days. At both time-points, the proportion of patients with a favorable outcome was higher for DS-1040 than for placebo, regardless of DS-1040 dosage (Fig. 5). However, there was no apparent relationship between DS-1040 dosage and the probability of favorable outcome at either 30 or 90 days.

\subsection{Exploratory Endpoints}

\subsection{1 $\mathrm{TICl}$ Grade}

TICI grade score was available for 40 patients (31 in the DS-1040 group and 9 in the placebo group). Except for one patient who received DS-1040 $1.2 \mathrm{mg}$, all patients achieved either TICI grade $2 \mathrm{~B}$ or grade 3 reperfusion after thrombectomy. The percentage of patients with complete (TICI grade 
Table 4 Pharmacokinetic parameters of DS-1040

\begin{tabular}{llllllllll}
\hline Cohort & Dosage $(\mathrm{mg})$ & $n^{\mathrm{a}}$ & $C_{\max }(\mathrm{ng} / \mathrm{mL})$ & $t_{\max }(\mathrm{h})$ & $\begin{array}{l}\mathrm{AUC} \mathrm{C}_{0-24 \mathrm{hr}} \\
(\mathrm{ng} \times \mathrm{h} / \mathrm{mL})\end{array}$ & $\mathrm{AUC}_{\text {last }}(\mathrm{ng} \times \mathrm{h} / \mathrm{mL})$ & $t_{1 / 2}(\mathrm{~h})$ & $\mathrm{CL}(\mathrm{L} / \mathrm{h})$ & $V_{\mathrm{ss}}(\mathrm{L})$ \\
\hline 1 & 0.6 & 6 & $17.2 \pm 6.25$ & $2.21 \pm 2.18$ & $151 \pm 40.5$ & $111 \pm 45.5$ & $4.61^{\mathrm{b}}$ & $3.39^{\mathrm{b}}$ & $17.6^{\mathrm{b}}$ \\
2 & 1.2 & 11 & $29.7 \pm 7.50$ & $4.67 \pm 2.29$ & $267 \pm 61.6$ & $275 \pm 72.2$ & $16.8 \pm 1.74^{\mathrm{c}}$ & $3.03 \pm 0.23^{\mathrm{c}}$ & $22.6 \pm 2.43^{\mathrm{c}}$ \\
3 & 2.4 & 10 & $60.6 \pm 11.8$ & $5.11 \pm 1.85$ & $503 \pm 154$ & $570 \pm 230$ & $19.5 \pm 10.5^{\mathrm{d}}$ & $4.62 \pm 1.85^{\mathrm{d}}$ & $43.3 \pm 24.4^{\mathrm{d}}$ \\
4 & 4.8 & 3 & $141.0 \pm 61.7$ & $5.96 \pm 0.03$ & $1320 \pm 752$ & $1550 \pm 962$ & $29.7 \pm 2.35$ & $3.71 \pm 1.73$ & $46.5 \pm 16.3$ \\
\hline
\end{tabular}

All data are expressed as mean \pm standard deviation except where $n=1$

$A U C$ area under the plasma concentration-time curve, $A U C_{0-24 h}$ AUC from zero to $24 \mathrm{~h}, A U C_{\text {last }}$ AUC from zero to last measurable concentration, $C L$ clearance, $C_{\max }$ maximum plasma concentration, $n$ number of subjects, $t_{1 / 2}$ elimination half-life, $t_{\max }$ time to $\mathrm{C}_{\max }$, Vss volume of distribution at steady state

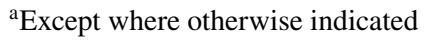

$\mathrm{b}_{n=1}$

${ }^{\mathrm{c}} n=3$

$\mathrm{d}_{n}=5$
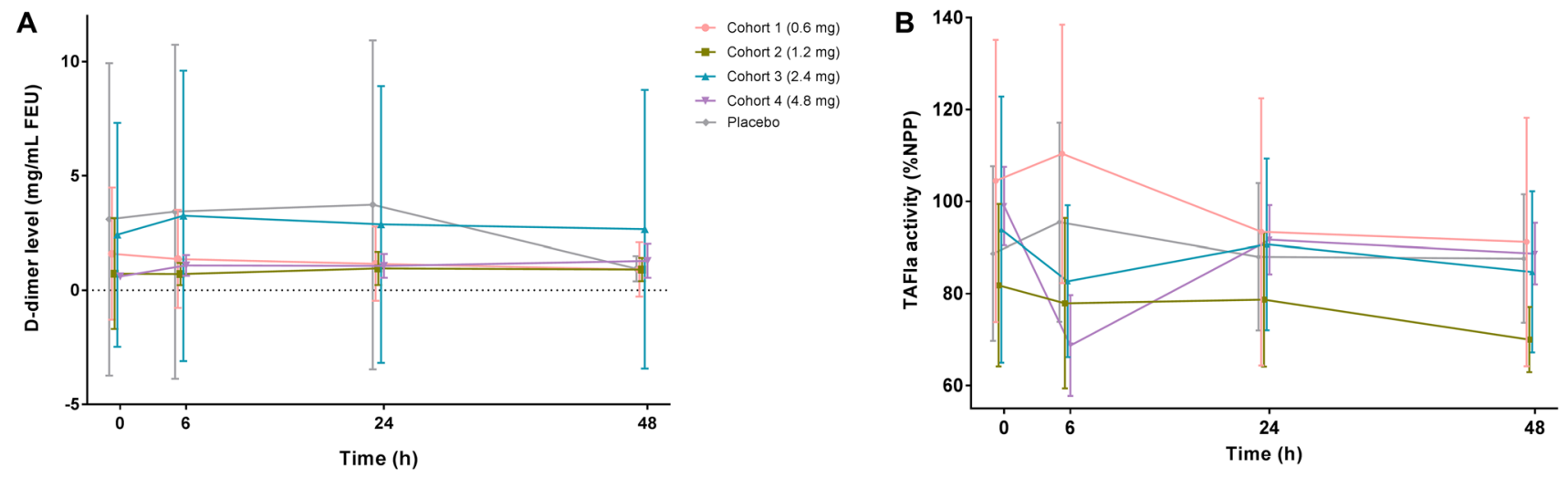

Fig. 3 Effects of DS-1040 and placebo on A D-dimer levels, and B TAFIa activity. Data points and error bars represent the mean and standard deviation, respectively. FEU fibrinogen equivalent units,

3) reperfusion was $44.4 \%(n=4)$ in the placebo group and $51.6 \%(n=16)$ in the DS-1040 group. There was no apparent relationship between DS-1040 treatment (or dosage) and the probability of achieving TICI grade 3 reperfusion.

\section{Discussion}

DS1040-A-J110 was the first clinical trial of DS-1040 in patients with AIS in Japan, and, indeed, one of the first studies of DS-1040 in any indication. Accordingly, its primary objective was to evaluate the safety of DS-1040, with the primary endpoints being the incidence of symptomatic or asymptomatic ICH or major extracranial bleeding. Over a range of single doses of DS-1040 from 0.6 to $4.8 \mathrm{mg}$, given by IV infusion over $6 \mathrm{~h}$, we found no evidence of symptomatic ICH in the first $36 \mathrm{~h}$ after the start of treatment, and no major extracranial bleeding in the first $96 \mathrm{~h}$. In the current
NPP normal pooled plasma, TAFI thrombin-activatable fibrinogen inhibitor, TAFI $a$ activated form of TAFI

study, asymptomatic ICH was more common in patients receiving DS-1040 than placebo (37.5\% vs $11.1 \%$ ) but had no impact on the outcome of treatment. In a sub-analysis of data from the RESCUE-Japan registry, the incidence of asymptomatic ICH among Japanese patients treated with thrombectomy for large vessel occlusion was $26.4 \%$, compared with $13.7 \%$ in patients who received conservative therapy or thrombolysis $(p<0.001)$ [14]. In the current study, the incidence of asymptomatic ICH in the placebo group tended to be lower than in the RESCUE-Japan registry.

Thus, our study confirms the conclusions of earlier work [9-11], which suggested that the potential of DS-1040 to cause clinically significant bleeding events is low. Additionally, DS-1040 was well tolerated, with drug-related TEAEs occurring in only one DS-1040-treated patient. Bleeding events, including major bleeding, occurred at a similar frequency in the placebo and DS-1040 groups, and there were no serious drug-related TEAEs. 
Fig. 4 Mean change in NIHSS score from baseline to $24 \mathrm{~h}$. Error bars indicate standard deviation. NIHSS National Institutes of Health Stroke Scale

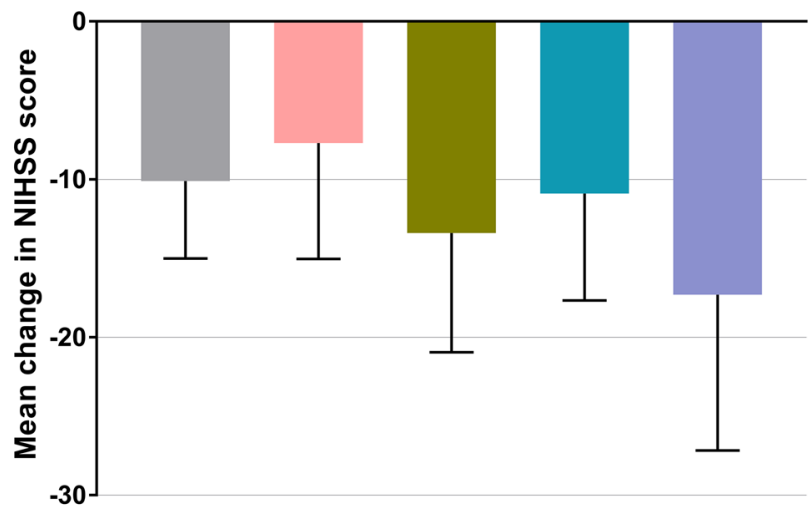

Placebo $(n=9)$

DS-1040 0.6 mg $(n=6)$

DS-1040 $1.2 \mathrm{mg}(\mathrm{n}=12)$

DS-1040 $2.4 \mathrm{mg}(\mathrm{n}=11)$

DS-1040 $4.8 \mathrm{mg}(\mathrm{n}=3)$
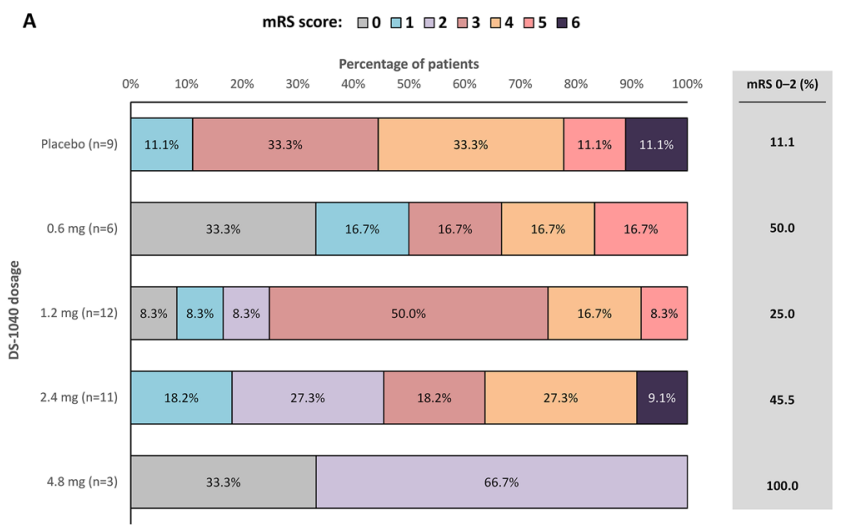

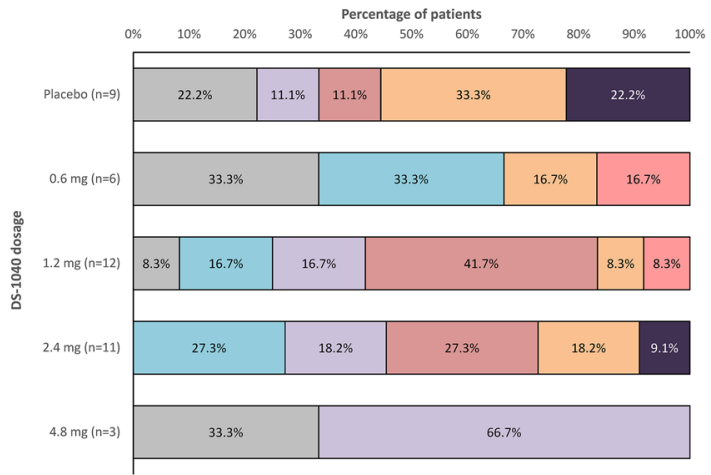

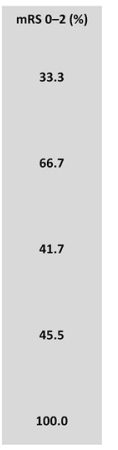

Fig. 5 Modified Rankin Scale scores at A 30 and B 90 days after the start of treatment. $m R S$ modified Rankin Scale

Alteplase and thrombectomy are standard treatments for AIS and should ideally be used in combination in eligible patients. Alteplase remains a standard of care for patients with radiologically confirmed AIS, provided that it can be administered within $9 \mathrm{~h}$ of symptom onset and that there are no contraindications to its use $[15,16]$. However, the recanalization rate after alteplase is only approximately $40 \%$ in patients with distal MCA occlusion and $<10 \%$ in those with ICA occlusion [17]. In accordance with international and Japanese guidelines, thrombectomy is suitable only when a major artery is occluded [18-20].

There is undoubtedly a need for new additive or substitutive approaches, pharmacologic and otherwise, to the management of AIS with the potential to preserve brain tissue, further reduce mortality, and prevent disability resulting from neurologic damage. The discovery of TAFI and its activated form, TAFIa, which acts as a physiologic 'brake' on plasmin-mediated fibrinolysis [21], led to the development of several novel TAFIa inhibitors that demonstrated fibrinolytic activity in animal models and early clinical trials
[22-25]. However, to date, none of these agents has been made commercially available.

The effects of DS-1040 on pharmacodynamic parameters and on NIHSS and mRS scores are challenging to interpret, with limited evidence of a dose-effect relationship or marked differences between DS-1040 and placebo. Although TAFIa activity levels decreased in DS-1040 recipients at one or more time-points, consistent, dose-related increases in D-dimer were not observed. Because blood clots in the brain tend to be small, changes in D-dimer levels may be too subtle to detect in peripheral blood.

It could be suggested that, in general, dose-proportionality was not observed because of the small number of patients in the highest dosage group, and because the dosages of DS-1040 used were lower than in previous studies [10, 11]. However, these previous studies, which used a wider range of doses, also failed to demonstrate dose-proportional effects of DS-1040 on D-dimer levels [10, 11]. In contrast, TAFIa activity levels have been shown to be reduced by DS-1040 in a dose-proportional manner [9]. 
There was also no clear relationship between DS-1040 dosage and change in either the NIHSS score or the proportion of patients with a favorable outcome (mRS score 0-2). All but one patient (who received DS-1040 1.2 mg) in the overall study population achieved successful recanalization (TICI2b-3) with thrombectomy; however, a favorable outcome (mRS score $0-2$ ) was seen in $~ 25 \%$ to $100 \%$ of patients in the DS-1040 arms compared with only $11 \%$ of patients in the placebo arm, despite successful recanalization. Although DS-1040 $4.8 \mathrm{mg}$ performed better than placebo with respect to these measures, no firm conclusions can be drawn because only three patients received DS-1040 $4.8 \mathrm{mg}$.

Strict adherence to a trial protocol, particularly with respect to enrollment, drug administration and blood sampling, can be very challenging in the context of a medical emergency such as AIS. Therefore, a strength of our study was the clinical trial implementation system that we developed for use at each medical institution, since communication and cooperation between the sub-principal investigator, clinical research coordinator, and clinical trial staff was considered critical to ensure the validity and robustness of the data obtained.

We acknowledge the limitations of our trial, including the small number of patients included in each cohort; this precluded formal statistical analysis. Consequently, no firm conclusions can be drawn with regard to differences between DS-1040 doses, or between DS-1040 and placebo, for any of the secondary endpoints. Furthermore, our study was conducted exclusively in Japanese patients, and so the results may not be generalizable to other populations. A Phase Ib/II placebo-controlled trial (clinicaltrials.gov identifier: NCT02586233) of DS-1040 in patients with AIS has been conducted in Europe, North America, South Korea, Taiwan, and Australia. The preliminary results of this trial are available online and are expected to be published in due course.

\section{Conclusions}

In this Phase I study, single IV doses of DS-1040 0.6-4.8 $\mathrm{mg}$ were safe and well tolerated in Japanese patients with AIS undergoing thrombectomy. Further clinical research is needed to fully investigate the efficacy and safety of DS-1040 in a wider range of patients with AIS.

Supplementary Information The online version contains supplementary material available at https://doi.org/10.1007/s40261-021-01112-8.

Acknowledgments Editorial assistance with the preparation of this manuscript was provided by Richard Crampton of inScience Communications, Springer Healthcare. This assistance was funded by Daiichi Sankyo Co., Ltd.

\section{Declarations}

Funding The study was funded by Daiichi Sankyo Co., Ltd.

Conflicts of Interest Nobuyuki Sakai received honoraria from Daiichi Sankyo in relation to the organization of this study and for non-related work, and non-related honoraria from Asahi-Intec, Biomedical Solutions, Medtronic, Stryker, and Terumo. Masataka Takeuchi reports the receipt of lecture fees from Stryker. Hirotoshi Imamura has received non-related honoraria from Medtronic and Stryker. Shinichi Yoshimura has received speakers' bureau fees or honoraria from Boehringer Ingelheim, Daiichi Sankyo, Bayer, Bristol-Myers Squibb, Otsuka Pharmaceutical, Stryker, Kaneka Medics and Medtronic. Kazunori Toyoda reports personal fees from Daiichi Sankyo, Bayer Yakuhin, Bristol-Myers Squibb, Takeda and Nippon Boehringer-Ingelheim, unrelated to the submitted work. Hiroshi Yamagami reports receipt of research grants from Bristol-Myers Squibb; lecture fees from Stryker, Terumo, Medtronic, Johnson and Johnson, Bayer, Daiichi Sankyo, Bristol-Myers Squibb, Boehringer Ingelheim and Otsuka Pharmaceutical; and membership of advisory boards for Daiichi Sankyo in a nonrelated trial. Shigeru Fujimoto has received lecture fees from Takeda, Nippon Boehringer Ingelheim, Dai-Nippon Sumitomo Pharma, Bayer Yakuhin, Otsuka Pharmaceutical, Pfizer Japan, Daiichi Sankyo, Eisai, Bristol-Myers Squibb, Sanofi K.K. and MSD K. K., and received an honorarium from Daiichi Sankyo in relation to the organization of this study. Norihito Shimamura, Hiromichi Naito, Naoto Kimura, Osamu Masuo, Nobuyuki Hirotsune, Kenichi Morita, and Hideyuki Ishihara have no conflicts of interest to declare. Takafumi Nakatsu, Naoki Miyoshi and Miharu Suda are employees of Daiichi Sankyo.

Ethics approval The trial was performed in compliance with the Declaration of Helsinki, the International Conference on Harmonization Integrated Guideline for Good Clinical Practice, and additional regulatory codes applicable in Japan. The trial protocol was approved by the Institutional Review Board at each participating center before any patients were enrolled at that center.

Consent to participate All patients, or a legally competent representative, gave written informed consent to participate.

Consent for publication Not applicable.

Availability of data and material De-identified individual participant data (IPD) and applicable supporting clinical trial documents (study protocol, statistical analysis plan, informed consent form, clinical study report and analytic code) may be available upon request at https://vivli. org/. In cases where clinical trial data and supporting documents are provided pursuant to company policies and procedures, Daiichi Sankyo will continue to protect the privacy of clinical trial participants. Details on data sharing criteria and the procedure for requesting access can be found at this web address: https://vivli.org/ourmember/daiichi-sankyo/

Code availability Not applicable.

Authors' contributions Nobuyuki Sakai contributed to study design and preparation of manuscript. Masataka Takeuchi, Hirotoshi Imamura, Norihito Shimamura, Shinichi Yoshimura, Hiromichi Naito, Naoto Kimura, Osamu Masuo, Nobuyuki Hirotsune, Kenichi Morita, Kazunori Toyoda, Hiroshi Yamagami and Hideyuki Ishihara contributed to patient enrollment. Shigeru Fujimoto contributed to data analysis and determining outcomes. Takafumi Nakatsu, Naoki Miyoshi and Miharu Suda contributed to study design, statistical analysis and preparation of the manuscript. All authors read and approved the drafts, including the final version for submission, and agree to be accountable for all aspects of the work. 
Open Access This article is licensed under a Creative Commons Attribution-NonCommercial 4.0 International License, which permits any non-commercial use, sharing, adaptation, distribution and reproduction in any medium or format, as long as you give appropriate credit to the original author(s) and the source, provide a link to the Creative Commons licence, and indicate if changes were made. The images or other third party material in this article are included in the article's Creative Commons licence, unless indicated otherwise in a credit line to the material. If material is not included in the article's Creative Commons licence and your intended use is not permitted by statutory regulation or exceeds the permitted use, you will need to obtain permission directly from the copyright holder. To view a copy of this licence, visit http://creativecommons.org/licenses/by-nc/4.0/.

\section{References}

1. Global Burden of Disease Study 2019 (GBD 2019): Institute for health metrics and evaluation (ihme), university of washington; 2020. http://ghdx.healthdata.org/gbd-results-tool?params= gbd-api-2019-permalink/ad2ec598c429de9a8033ba1767e33683 Accessed 4 Dec 2020

2. Herpich F, Rincon F. Management of acute ischemic stroke. Crit Care Med. 2020;48(11):1654-63. https://doi.org/10.1097/CCM. 0000000000004597

3. Goyal M, Menon BK, van Zwam WH, Dippel DW, Mitchell PJ, Demchuk AM, et al. Endovascular thrombectomy after largevessel ischaemic stroke: a meta-analysis of individual patient data from five randomised trials. Lancet (London, England). 2016;387(10029):1723-31. https://doi.org/10.1016/s01406736(16)00163-x.

4. El Amki M, Wegener S. Improving cerebral blood flow after arterial recanalization: a novel therapeutic strategy in stroke. Int J Mol Sci. 2017. https://doi.org/10.3390/ijms18122669.

5. Marto JP, Strambo D, Hajdu SD, Eskandari A, Nannoni S, Sirimarco G, et al. Twenty-four-hour reocclusion after successful mechanical thrombectomy: associated factors and long-term prognosis. Stroke. 2019;50(10):2960-3. https://doi.org/10.1161/ STROKEAHA.119.026228.

6. Mosimann PJ, Kaesmacher J, Gautschi D, Bellwald S, Panos L, Piechowiak E, et al. Predictors of unexpected early reocclusion after successful mechanical thrombectomy in acute ischemic stroke patients. Stroke. 2018;49(11):2643-51. https://doi.org/10. 1161/STROKEAHA.118.021685.

7. Zaidat OO, Castonguay AC, Gupta R, Sun CJ, Martin C, Holloway WE, et al. North american solitaire stent retriever acute stroke registry: post-marketing revascularization and clinical outcome results. J Neurointerv Surg. 2018;10(Suppl 1):i45-9. https://doi. org/10.1136/neurintsurg-2013-010895.rep.

8. Saver JL, Goyal M, Bonafe A, Diener HC, Levy EI, Pereira VM, et al. Stent-retriever thrombectomy after intravenous t-pa vs. T-pa alone in stroke. N Engl J Med. 2015;372(24):2285-95. https://doi. org/10.1056/NEJMoa1415061.

9. Noguchi K, Edo N, Miyoshi N, Isobe A, Watanabe A, Ito Y, et al. Fibrinolytic potential of ds-1040, a novel orally available inhibitor of activated thrombin-activatable fibrinolysis inhibitor (tafia). Thromb Res. 2018;168:96-101. https://doi.org/10.1016/j.throm res.2018.06.010

10. Zhou J, Kochan J, Yin O, Warren V, Zamora C, Atiee G, et al. A first-in-human study of ds-1040, an inhibitor of the activated form of thrombin-activatable fibrinolysis inhibitor, in healthy subjects. J Thromb Haemost. 2017;15(5):961-71. https://doi.org/10.1111/ jth.13658.

11. Zhou J, Limsakun T, Yin O, Warren V, Zamora C, Atiee G, et al. First-in-human study to assess the safety, pharmacokinetics, and pharmacodynamics of an oral formulation of ds-1040, an inhibitor of the activated form of thrombin-activatable fibrinolysis inhibitor, in healthy subjects. J Clin Pharmacol. 2019;59(12):1669-77. https://doi.org/10.1002/jcph.1474.

12. Tomsick T, Broderick J, Carrozella J, Khatri P, Hill M, Palesch Y, et al. Revascularization results in the interventional management of stroke ii trial. AJNR Am J Neuroradiol. 2008;29(3):582-7. https://doi.org/10.3174/ajnr.A0843.

13. Vanassche T, Rosovsky RP, Moustafa F, Büller HR, Segers A, Patel I, et al. Inhibition of thrombin activatable fibrinolysis inhibitor (tafi) to accelerate clot lysis in patients with acute pulmonary embolism: a Phase 2 randomized study (abstract oc 73.1). Philadelphia: International Society on Thrombosis and Hemostasis Virtual Congress; 2021.

14. Enomoto Y, Yoshimura S, Egashira Y, Yamagami H, Sakai N. The risk of intracranial hemorrhage in japanese patients with acute large vessel occlusion; subanalysis of the rescue-japan registry. J Stroke Cerebrovasc Dis. 2016;25(5):1076-80. https://doi.org/10. 1016/j.jstrokecerebrovasdis.2015.12.022.

15. Powers WJ, Rabinstein AA, Ackerson T, Adeoye OM, Bambakidis NC, Becker K, et al. 2018 guidelines for the early management of patients with acute ischemic stroke: a guideline for healthcare professionals from the american heart association/american stroke association. Stroke. 2018;49(3):e46-110. https://doi.org/10.1161/ STR.0000000000000158.

16. Campbell BCV, Ma H, Ringleb PA, Parsons MW, Churilov L, Bendszus M, et al. Extending thrombolysis to 4-5-9 h and wakeup stroke using perfusion imaging: a systematic review and meta-analysis of individual patient data. Lancet (London, England). 2019;394(10193):139-47. https://doi.org/10.1016/s01406736(19)31053-0.

17. Saqqur M, Uchino K, Demchuk AM, Molina CA, Garami Z, Calleja $S$, et al. Site of arterial occlusion identified by transcranial doppler predicts the response to intravenous thrombolysis for stroke. Stroke. 2007;38(3):948-54. https://doi.org/10.1161/01. STR.0000257304.21967.ba.

18. Turc G, Bhogal P, Fischer U, Khatri P, Lobotesis K, Mazighi M, et al. European stroke organisation (eso)—European society for minimally invasive neurological therapy (esmint) guidelines on mechanical thrombectomy in acute ischaemic strokeendorsed by stroke alliance for europe (safe). Eur Stroke J. 2019;4(1):6-12. https://doi.org/10.1177/2396987319832140.

19. Powers WJ, Rabinstein AA, Ackerson T, Adeoye OM, Bambakidis NC, Becker K, et al. Guidelines for the early management of patients with acute ischemic stroke: 2019 update to the 2018 guidelines for the early management of acute ischemic stroke: a guideline for healthcare professionals from the american heart association/american stroke association. Stroke. 2019;50(12):e344-418. https://doi.org/10.1161/STR.0000000000 000211.

20. Japan Stroke Society Committee on Guidelines for the Management of Stroke: Japanese guidelines for the management of stroke 2015. https://www.jsts.gr.jp/img/guideline2015_tuiho2019_10.pdf (Updated 2019). Accessed 1 Dec 2020.

21. Willemse JL, Heylen E, Nesheim ME, Hendriks DF. Carboxypeptidase $\mathrm{u}$ (tafia): a new drug target for fibrinolytic therapy? J Thromb Haemost. 2009;7(12):1962-71. https://doi.org/10.1111/j. 1538-7836.2009.03596.x.

22. Foley JH, Kim PY, Mutch NJ, Gils A. Insights into thrombin activatable fibrinolysis inhibitor function and regulation. J Thromb Haemost. 2013;11(Suppl 1):306-15. https://doi.org/10.1111/jth. 12216.

23. Suzuki K, Muto Y, Fushihara K, Kanemoto K, Iida H, Sato E, et al. Enhancement of fibrinolysis by ef6265 [(s)-7-amino-2-[[[(r)2-methyl-1-(3-phenylpropanoylamino)propyl]hydroxyphosphinoy 1] methyl]heptanoic acid], a specific inhibitor of plasma 
carboxypeptidase b. J Pharmacol Exp Ther. 2004;309(2):607-15. https://doi.org/10.1124/jpet.103.062729.

24. Wang YX, da Cunha V, Vincelette J, Zhao L, Nagashima M, Kawai K, et al. A novel inhibitor of activated thrombin activatable fibrinolysis inhibitor (tafia) - part ii: enhancement of both exogenous and endogenous fibrinolysis in animal models of thrombosis. Thromb Haemost. 2007;97(1):54-61.

25. Wang YX, Zhao L, Nagashima M, Vincelette J, Sukovich D, Li W, et al. A novel inhibitor of activated thrombin-activatable fibrinolysis inhibitor (tafia) — part i: pharmacological characterization. Thromb Haemost. 2007;97(1):45-53.

\section{Authors and Affiliations}

\section{Nobuyuki Sakai ${ }^{1} \cdot$ Masataka Takeuchi $^{2} \cdot$ Hirotoshi Imamura $^{1} \cdot$ Norihito Shimamura $^{3} \cdot$ Shinichi Yoshimura $^{4}$. Hiromichi Naito ${ }^{5}$. Naoto Kimura ${ }^{6} \cdot$ Osamu Masuo ${ }^{7} \cdot$ Nobuyuki Hirotsune $^{8} \cdot$ Kenichi Morita $^{9} \cdot$ Kazunori Toyoda $^{10}$. Hiroshi Yamagami ${ }^{11} \cdot$ Hideyuki Ishihara $^{12} \cdot$ Takafumi Nakatsu $^{13} \cdot$ Naoki Miyoshi $^{13} \cdot$ Miharu Suda $^{13}$. \\ Shigeru Fujimoto ${ }^{14}$}

1 Kobe City Medical Center General Hospital, 2-1-1 Minatojima Minamimachi, Chuo-ku, Kobe, Hyogo 650-0047, Japan

2 Seisho Hospital, Odawara, Kanagawa, Japan

3 Hirosaki University Hospital, Hirosaki, Aomori, Japan

4 Hyogo College of Medicine, Nishinomiya, Hyogo, Japan

5 Funabashi Municipal Medical Center, Funabashi, Chiba, Japan

6 Iwate Prefectural Central Hospital, Morioka, Iwate, Japan

7 Yokohama Municipal Citizen's Hospital, Yokohama, Kanagawa, Japan
8 Hiroshima City Hiroshima Citizens Hospital, Hiroshima, Hiroshima, Japan

9 Niigata City General Hospital, Niigata, Niigata, Japan

10 National Cerebral and Cardiovascular Center, Suita, Osaka, Japan

11 National Hospital Organization Osaka National Hospital, Osaka, Osaka, Japan

12 Yamaguchi University Hospital, Ube, Yamaguchi, Japan

13 Daiichi Sankyo Co., Ltd, Chuo-ku, Tokyo, Japan

14 Jichi Medical University Hospital, Shimotsuke, Tochigi, Japan 